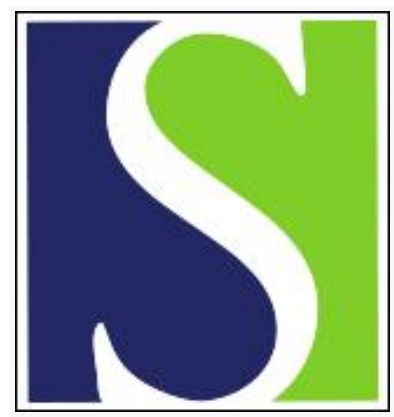

Scand J Work Environ Health 2013;39(1):66-75

https://doi.org/10.5271/sjweh.3311

Published online: 27 Jun 2012, Issue date: Jan 2013

Effectiveness of a worksite lifestyle intervention on vitality, work engagement, productivity, and sick leave: results of a randomized controlled trial

by Strijk JE, Proper KI, van Mechelen W, van der Beek AJ

Good quality effect studies (RCT) concerning specifically older workers are still lacking. Therefore, the results of this study are innovative and provide valuable information for occupational health epidemiology as well as employers. As for policy implications, implementation of worksite yoga facilities could be a useful strategy to promote vitality-related work outcomes, but only if high compliance can be maximized.

Affiliation: Department of Public and Occupational Health, EMGO+ Institute for Health and Care Research, VU University Medical Center, Van der Boechorststraat 7, 1081 BT Amsterdam, The Netherlands. a.vanderbeek@vumc.nl

Refers to the following texts of the Journal: $2002 ; 28(2): 85-93$ 2002;28(2):75-84 1997;23 suppl 1:49-57 1992;18 suppl 2:8-10

The following articles refer to this text: 2013;39(3):217-220; 2015;41(5):421-424; 2019;45(5):514-519

Key terms: hospital worker; intervention; lifestyle intervention; older worker; productivity; randomized controlled trial; sick leave; sickness absence; vitality; work engagement; worksite health promotion; worksite intervention; worksite vitality intervention; yoga

This article in PubMed: www.ncbi.nlm.nih.gov/pubmed/22740100

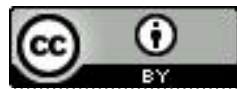




\title{
Effectiveness of a worksite lifestyle intervention on vitality, work engagement, productivity, and sick leave: results of a randomized controlled trial
}

\author{
by Jorien E Strijk, PhD, ${ }^{1}$ Karin I Proper, PhD, ${ }^{1,2}$ Willem van Mechelen, PhD, 1, 2 Allard J van der Beek, PhD 1,2
}

\begin{abstract}
Strijk JE, Proper KI, van Mechelen W, van der Beek AJ. Effectiveness of a worksite lifestyle intervention on vitality, work engagement, productivity, and sick leave: results of a randomized controlled trial. Scand $J$ Work Environ Health. 2013;39(1):66-75. doi:10.5271/sjweh.3311
\end{abstract}

\begin{abstract}
Objective A worksite lifestyle intervention aiming to improve lifestyle behaviors could be an effective tool to keep older workers vital, and thereby prolong their labor participation. This study evaluates the effectiveness of such an intervention on vitality, work engagement, productivity and sick leave.
\end{abstract}

Methods In a randomized controlled trial design, 367 workers (control group: N=363) received a 6-month intervention, which included two weekly guided group sessions: one yoga and one workout, as well as one weekly session of aerobic exercising, without face-to-face instruction, and three individual coach visits aimed at changing workers' lifestyle behavior by goal setting, feedback, and problem-solving strategies. Furthermore, free fruit was provided at the guided sessions. Data on work-related vitality (UWES vitality scale), general vitality (RAND-36 vitality scale), work engagement (UWES), productivity (single item scoring 0-10), and sick leave (yes/no past 3 months) were collected using questionnaires at baseline $(\mathrm{N}=730)$, and at $6-(\mathrm{N}=575)$ and 12-months $(\mathrm{N}=500)$ follow-up. Effects were analyzed according to the intention-to-treat principle with complete cases $(\mathrm{N}=500)$ and imputed data $(\mathrm{N}=730)$.

Results There were no significant differences in vitality, work engagement, productivity, and sick leave between the intervention and control group workers after either 6- and 12-months follow-up. Yoga and workout subgroup analyses showed a 12 -month favorable effect on work-related vitality $[\beta=0.14,95 \%$ confidence interval $(95 \%$ CI) $0.04-0.28$ ] and general vitality $(\beta=2.9,95 \%$ CI $0.02-5.9)$ among high yoga compliers. For high workout compliers, this positive trend was also seen, but it was not statistically significant.

Conclusions Implementation of worksite yoga facilities could be a useful strategy to promote vitality-related work outcomes, but only if high compliance can be maximized. Therefore, impeding factors for participation should be investigated in more detail in future research.

Key terms lifestyle intervention; sickness absence; worksite health promotion; yoga.

Over the next decades, challenges in work life will arise due to the expected structural labor shortage and the aging workforce (1). These challenges include the prevention of early retirement and demands for increased employability and labor participation. An important contributor to early retirement and decreased employability is the health status of workers $(2,3)$, which may decline with aging due to lower physical capacity and higher prevalence of chronic diseases (4-6). In addition, healthy workers are more productive, have lower risks for sick leave, and are more engaged in their jobs. Thus, in order to face the upcoming challenges in work life, it is important to keep older workers vital and healthy.

Vitality and health are two concepts that are closely related because, similar to health, vitality consists of both mental and physical factors. Regarding the mental factors, vitality reflects well-being, lower levels of fatigue, mental resilience, and perseverance (7-11). With respect to the physical factors, vitality is characterized by high energy levels and feeling "strong and fit" (11). In occupational health, vitality has been described as one of the three dimensions of work engagement and

1 Department of Public and Occupational Health, EMGO+ Institute for Health and Care Research, VU University Medical Center, Amsterdam, The Netherlands.

2 Body@Work, Research Center Physical Activity, Work and Health, TNO-VUmc, Amsterdam, The Netherlands. 
is characterized by "feeling full of energy, strong and fit, and being able to keep on working indefatigably"(11).

In the Vital@Work study, it was hypothesized that a worksite health promotion (WHP) program aimed at improving workers' lifestyles could be considered as a potentially effective tool to keep older workers vital and, thereby, positively affect relevant work-related outcomes related to prolonged employability, such as work engagement, productivity, and sick leave (12). The specific aims of the Vital@Work intervention were that older workers would improve their: (i) mental factors of vitality by relaxation exercises (ie, guided yoga sessions); (ii) physical factors of vitality by vigorous intensity physical activities (ie, guided and unsupervised workout sessions); and (iii) fruit intake (ie, free fruit at guided sessions) (12). The rationale behind this, which is described extensively elsewhere (12), was based on scientific literature showing that healthy lifestyle choices (ie, physical activity, relaxation, and fruit intake) contribute to better health outcomes, eg, improved mental health, perceived higher energy levels, less fatigue, improved quality of life, and lower risk for chronic diseases (13-17). Specifically for the physical component of vitality, indirect positive effects of vigorous physical activity can be expected through improved levels of aerobic capacity [ie, maximal oxygen consumption $\left.\left(\mathrm{VO}_{2 \max }\right)\right]$. The latter was confirmed by earlier findings of the Vital@Work study showing that aerobic capacity was associated with vitality (18). As to the mental factors of vitality, it was hypothesized that these could be improved by relaxation exercises (ie, yoga). Although the beneficial effects of yoga are not widely reported yet, studies among patient populations showed favorable effects on mental health, energy, and well-being (19-22). In addition, a Swedish intervention study among 33 workers showed positive effects of yoga on psychological and physiological stress outcomes (23).

From the employer's perspective, investment in older workers' lifestyles and vitality is expected to beneficially affect important work-related outcomes, such as work engagement, productivity, and sick leave (24-27). The beneficial effects of WHP programs on health (28), aforementioned lifestyle behaviors $(29,30)$, and workrelated outcomes, such as sick leave and productivity, have indeed been reported (31-33). Although evidence in lacking, positive effects on work engagement can also be expected as healthy and vital workers are more engaged in their job (34).

Altogether, improving older workers' lifestyle can be considered a promising manner to affect vitality and work-related outcomes (such as sick leave, productivity, and work engagement) positively. After six months, the Vital@Work intervention was shown to be effective on increasing older workers' sport activities, fruit intake, and significantly decreased the need to recover from a day working (35). Although these findings are important for both the employee and employer, the latter may also be interested in work-related outcomes such as vitality, work engagement, productivity, and sick leave. Considering the above, the objective of this study was to investigate the effectiveness of the Vital@Work intervention on vitality, work engagement, productivity, and sick leave after both 6- (ie, short term) and 12-months follow-up (ie, sustainability of effects in the long term).

\section{Methods}

\section{Study population and design}

All workers aged $\geq 45$ years from two academic hospitals (ie, location A in Amsterdam and location B in Leiden) in the Netherlands were invited to participate, from location A in April 2009 and from location B in September of that same year (figure 1). A worker was considered eligible if he/she worked $\geq 16$ hours a week, gave written informed consent, and had no risk of developing adverse health effects when becoming physically active [as assessed by the Physical Activity Readiness Questionnaire (PAR-Q) (36)]. The Medical Ethics Committee of VU University Medical Center approved the study protocol. Details on the randomized controlled trial (RCT) design, intervention, and background have been described extensively elsewhere (12). The workers who consented to participate were, after baseline measurements, individually randomized to the intervention or control group using Random Allocation Software (version 1.0, May 2004, Isfahan University of Medical Sciences, Iran). After randomization, the research assistant informed each worker to which group he or she was allocated and did not reveal this allocation to the investigator responsible for data analyses. Blinding of participants or intervention providers was impossible. The sample size calculation was based on the primary study outcome [the Utrecht Engagement Scale (UWES) described extensively elsewhere (12)] and showed that 189 participants per group were needed at follow-up. After randomization, workers of both the intervention and control group received written information about a healthy lifestyle in general (ie, diet, physical activity, and relaxation). Additionally, the intervention group received a 6-month intervention consisting of a vitality exercise program (VEP) with provision of free fruit and combined with three individual visits to a personal vitality coach. The VEP consisted of: (i) once-weekly guided yoga group sessions aimed at relaxation exercises; and (ii) once-weekly guided aerobic workout group sessions aimed at improving aerobic fitness and increasing muscle strength. In addition, older workers were asked 


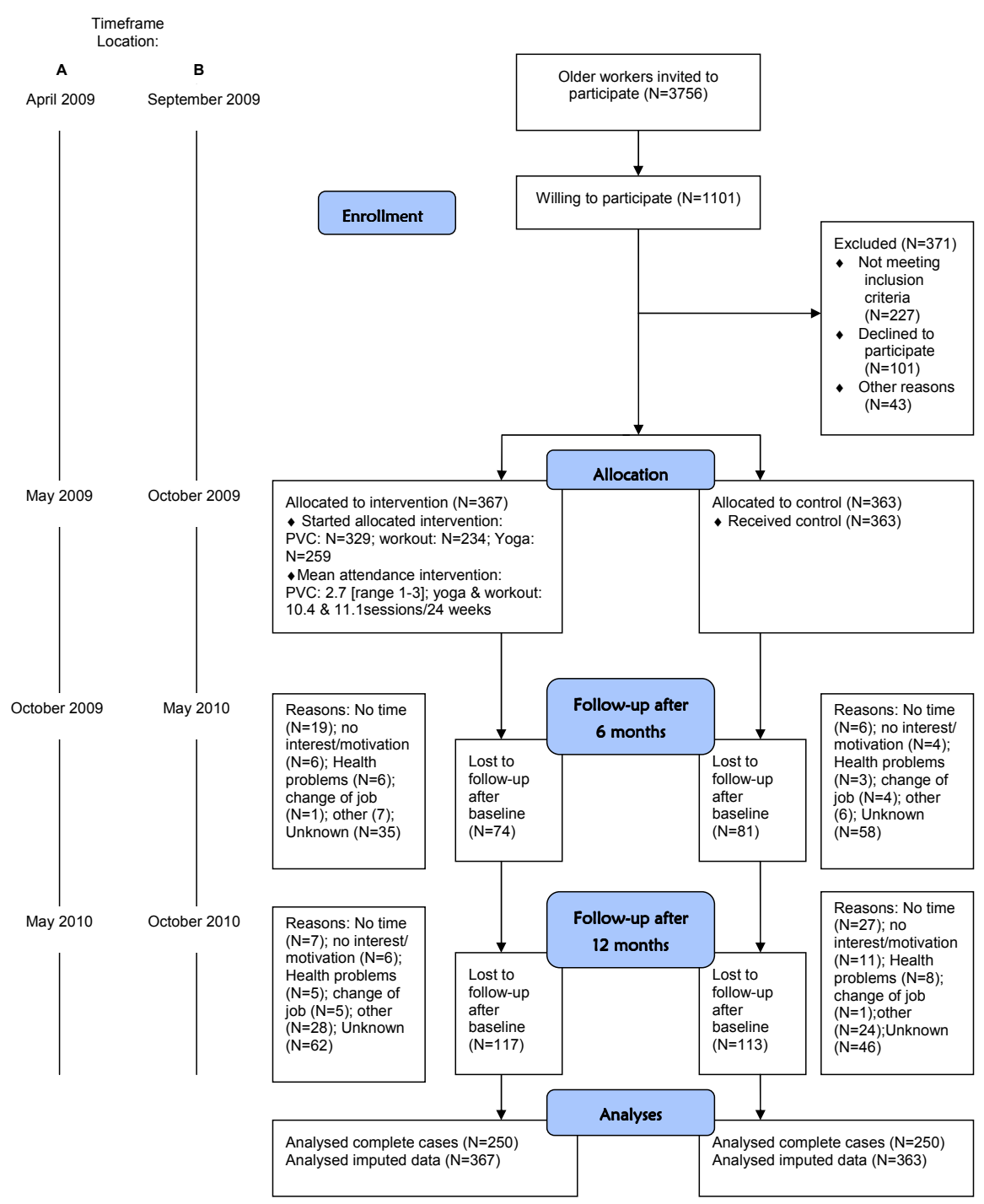

Figure 1. Timeframe and flow diagram of the Vital@Work study. to perform vigorous physical activity without face-toface instruction (eg, fitness, spinning, distance running) for $\geq 45$ minutes once a week. The yoga sessions, which were based on Hatha yoga (ie, asana, pranayama, and relaxation exercises), were guided by a qualified yoga instructor and included exercises consisting of (i) relaxation and preparation postures for the hips, shoulders, neck, feet, and hands while focusing on breathing, (ii) series of standing postures, forward bending postures and twists, and light back-bending postures, and (iii) total relaxation (ie, the "Savasana Corpse" pose) and meditation. Workout sessions were guided by certified fitness instructors and consisted of a warm-up followed by aerobic exercises, resistance training, and coolingdown. The intensity of the workout had to be $65-90 \%$ of the age-predicted maximum heart rate $\left(\mathrm{HR}_{\max }\right)(37)$. The resistance training was progressive in nature and provided stimulus to all major muscle groups. At the guided group sessions of the VEP there was free provision of fruit. The visits to the personal coach were based on psychological behavior changing theories, such as goal setting, feedback, and problem-solving strategies. These visits aimed to change workers' lifestyle behavior in both the short term (ie, 6 months), by attending the guided group sessions of the VEP and performing weekly unsupervised vigorous physical activities, as well as after 12 months (ie, sustainability of the newly adopted healthy lifestyle in the long term) (12). The first visit to the personal vitality coach was scheduled at the start of the intervention and was followed by two consecutive visits 4-6 weeks and 10-12 weeks after the first visit. During the 30-minute visits, five items were discussed: goal setting, confidence in achieving formulated goals, feedback on formulated goals, barriers to formulated goals, and problem solving. At the first visit, goal setting and confidence in achieving formulated 
goals were discussed. At the second and third visits, the same items were discussed, namely feedback on formulated goals, discussing barriers for formulated goals, and problem solving. At all visits, workers received advice on suitable vigorous physical activities they could perform on a regular basis. At both intervention locations, the implementation of the Vital@Work intervention was approved by senior management but workers did not have permission to participate during paid working time. To stimulate participation, the guided sessions and personal vitality coach visits were offered near the worksite during lunchtime and at the end of a working day.

\section{Outcome measures}

The primary outcome measure under study was vitality. In addition, secondary work-related outcomes measures (work engagement, productivity and sick leave) were evaluated. All outcomes were measured at baseline and 6 and 12 months later, between May 2009 and October 2010 (figure 1).

Vitality was the primary outcome and was measured by two questionnaires: (i) the RAND-36 vitality scale (38) was used to measure general vitality, and (ii) UWES was used to measure work-related vitality (11). The RAND-36 score consists of four items that refer to the past four weeks: (i) "Did you feel full of pep?", (ii) "Did you have a lot of energy?", (iii) "Did you feel worn out?", and (iv) "Did you feel tired?". The answers were rated on a six-point scale (from 1=all of the time to $6=$ none of the time) (11). The RAND-36 vitality score is calculated by:

\section{$\left[\frac{\text { summing the points of the aforementioned items }-4}{20}\right] \times 100$}

The RAND-36 score ranges from 0-100 points, with higher scores indicating a better subjective vitality, and has been shown to be sufficiently reliable and stable (38). UWES consists of six questions that refer to high levels of energy, fitness, resilience, willingness to invest effort, not being easily fatigued, and persistence in the face of difficulties. Answers are rated on a 7-point scale from $0=$ never to $6=$ daily. A higher score indicates better work-related vitality. UWES has been shown to have sufficient internal consistency (11).

Of the secondary work-related outcomes, productivity was measured using a single-item question from the WHO Health Productivity Questionnaire (WHO-HPQ) asking workers to report their overall productivity on a 10-point scale from 0-10 over the past 4 weeks (39). Information on sick leave (yes/no) was obtained from a single-item question from the Productivity and Disease Questionnaire (PRODISQ) (40) asking the workers about the number of times they stayed home from work due to health problems during the past three months.
Several variables were checked for confounding or effect modification and were assessed using a questionnaire. These variables were age (years), gender (female/male), education (low=elementary school or less, medium $=$ secondary education, and high $=$ college/ university), chronic disease status (yes/no), smoking (yes/no), intervention location (A: Amsterdam/B: Leiden), and marital status (having a partner: yes/no).

\section{Statistical analysis}

Independent t-test for continuous variables and Pearson's Chi-square tests for categorical and dichotomous variables were used to test differences in baseline and outcome measures between the intervention and control group and between completers and non-completers. The effectiveness of the intervention at 6 and 12 months follow-up was analyzed using linear regression (continuous outcomes, ie, vitality, work engagement, productivity) and logistic regression (dichotomous outcome, ie, sick leave) analyses, adjusted for the baseline levels of these outcomes. In addition to sick leave analyses, logtransformed data were used to analyze effectiveness on sick leave days for those having at least one sick leave episode during follow-up. All analyses were performed according to the intention-to-treat principle. As possible effects of missing participants should be considered, it is recommended to perform both complete cases and sensitivity analyses with imputed data (41). For the sensitivity analyses, all missing data on the outcome measure were imputed using multiple imputations (MI) based on multivariate imputation by chained equations $(42,43)$. The MI procedure was performed in PASW (version 18.0, SPSS Inc, Chicago, IL, USA), in which 40 different data sets were generated. By using Rubin's rules, PASW enabled the pooling of effects from these 40 data sets (44). Additional data analyses were performed to look for relationships between the main study outcome, the two vitality measures, and compliance of workers with the guided yoga and workout group sessions. Compliance with the guided group sessions was defined based on the mean of the followed yoga and workout group sessions, which were 10.4 and 11.1 sessions per 24 weeks, respectively. Compliance categories defined were: (i) workers in the control group ( $\mathrm{N}=363)$, (ii) workers in the intervention group who did not follow a guided session (yoga $\mathrm{N}=47$; workout $\mathrm{N}=62$ ), (iii) low compliance: $\leq$ mean number of sessions (yoga $\mathrm{N}=95$; workout $\mathrm{N}=89$ ), and (iv) high compliance: >mean number of sessions (yoga $\mathrm{N}=108$; workout $\mathrm{N}=99$ ). To test differences between these compliance groups, linear regression analyses were used with dummy variables for each compliance category, with the control group as reference category. Again, analyses were checked for potential confounders or effect modifiers. All statistical analyses were performed using PASW. As 
adding potential confounders to crude models did not change intervention effects $>10 \%$ and no effect modifiers were found, only crude effect estimates are presented in this paper.

\section{Results}

As presented in the study flow diagram (figure 1), a total of 730 workers completed the baseline questionnaire and were randomized to the intervention $(\mathrm{N}=367)$ or control group $(\mathrm{N}=363)$. Between October 2009 and September 2010, all follow-up measurements took place. In total, 500 workers completed the questionnaire 12 months after baseline and were, therefore, used for complete cases analyses. In addition, sensitivity analyses with imputed data among the total study population $(\mathrm{N}=730)$ were performed. The participants reported no adverse events of the intervention. In table 1, baseline characteristics of the study population are presented. No significant differences were found between study groups in any of the variables or between completers and non-completers.

Table 2 shows the intervention effects on workrelated (UWES) and general (RAND-36) vitality, work engagement, productivity, and sick leave after 6 and 12-months follow-up, revealed from complete cases analyses. Work-related vitality, work engagement and productivity remained more or less stable in both the control and intervention group, resulting in no significant differences for these outcomes between study groups after 6 and 12 months. For general vitality, the same pattern was seen with no significant changes over time within and between groups [ 6 months: $\beta=0.15$, 95\% confidence interval $(95 \% \mathrm{CI})-2.0-2.3 ; 12$ months: $\beta=1.5,95 \%$ CI $-0.73-3.8]$. Nevertheless, at 12-month follow-up, the intervention group had improved their general vitality by 1.9 versus 0.10 points among the workers in the control group, but this was not statistically significant (table 2 ).

Table 3 shows the relationships between yoga and workout group compliance and the two vitality measures. As for work-related vitality, there was a significant relationship for the high yoga compliance group [baseline mean 4.92, standard deviation (SD) $0.87,12$-month mean 5.08, SD $0.68, \beta=0.14,95 \%$ CI $0.04-0.28$ ], but not for high workout compliance $(\beta=0.11,95 \% \mathrm{CI}$ $-0.04-0.25$ ) (table 3 ). For general vitality, there was also a significant relationship for the high compliance group with respect to yoga (baseline mean 68.3, SD 16.2, 12 -month mean 71.3, SD 16.7, $\beta=2.9,95 \%$ CI 0.02-5.9), but not for the workout sessions $(\beta=2.3,95 \%$ CI $-0.67-$ 5.3) (table 3). Hence, high yoga compliance resulted in significantly better general and work-related vitality. In addition, the effect was stronger for those workers with high compliance with the yoga program as well as the workout sessions ( $\mathrm{N}=61 ; \beta=3.6,95 \%$ CI $0.19-7.1)$, but this was seen neither for work-related vitality nor the other compliance categories. Sensitivity analyses, with imputed data for missing values, showed similar significant findings when compared to the complete cases analyses. However, the effectiveness derived from the analyses with imputed data, were consistently smaller when compared to the complete cases (tables 2 and 3).

\section{Discussion}

No intervention effects were observed for vitality, work engagement, productivity, or sick leave. However, the results of the present study showed that high yoga compliers significantly increased their work-related and general vitality.

Table 1. Baseline characteristics of the Vital@Work study population ( $N=730)$. [ $N=$ number of older workers; $S D=s t a n d a r d ~ d e v i a t i o n]$

\begin{tabular}{|c|c|c|c|c|c|c|c|c|}
\hline \multirow[t]{2}{*}{ Baseline characteristics } & \multicolumn{4}{|c|}{ Intervention group } & \multicolumn{4}{|c|}{ Control group } \\
\hline & $\mathrm{N}$ & $\%$ & Mean & SD & $\mathrm{N}$ & $\%$ & Mean & SD \\
\hline Female & 274 & 74.7 & & & 277 & 76.3 & & \\
\hline \multicolumn{9}{|l|}{ Irregular working hours } \\
\hline Yes & 44 & 12.0 & & & 52 & 14.3 & & \\
\hline No & 323 & 88.0 & & & 311 & 85.7 & & \\
\hline Partner (yes) & 268 & 73.0 & & & 281 & 77.4 & & \\
\hline Chronic diseases (yes) & 207 & 59.1 & & & 217 & 57.0 & & \\
\hline Smoking (yes) & 38 & 10.4 & & & 40 & 11.0 & & \\
\hline \multicolumn{9}{|l|}{ Education level } \\
\hline Low & 42 & 11.4 & & & 32 & 8.8 & & \\
\hline Intermediate & 100 & 27.3 & & & 110 & 30.3 & & \\
\hline High & 225 & 61.3 & & & 221 & 60.9 & & \\
\hline Working hours per week & & & 30.4 & 7.3 & & & 29.8 & 7.0 \\
\hline Age (years) & & & 52.5 & 4.8 & & & 52.3 & 4.9 \\
\hline
\end{tabular}


Table 2. Mean and standard deviation for complete cases and imputed data for missing values on vitality, work engagement, productivity and sick leave for the intervention and control group at baseline $\left(T_{0}\right)$ and after 6 - and 12-months $\left(T_{6 m}\right.$ and $\left.T_{12 m}\right)$ follow-up after baseline. The intervention effects are also presented. [UWES= Utrecht Engagement Scale; min/wk=minutes per week; N=number of older workers; $\mathrm{SD}=$ standard deviation; $95 \% \mathrm{Cl}=95 \%$ confidence interval; $\mathrm{OR}=0 \mathrm{dds}$ ratio; $\Delta=$ mean difference between baseline and follow-up measure directly after the intervention ended (ie, 6 or 12 months)]

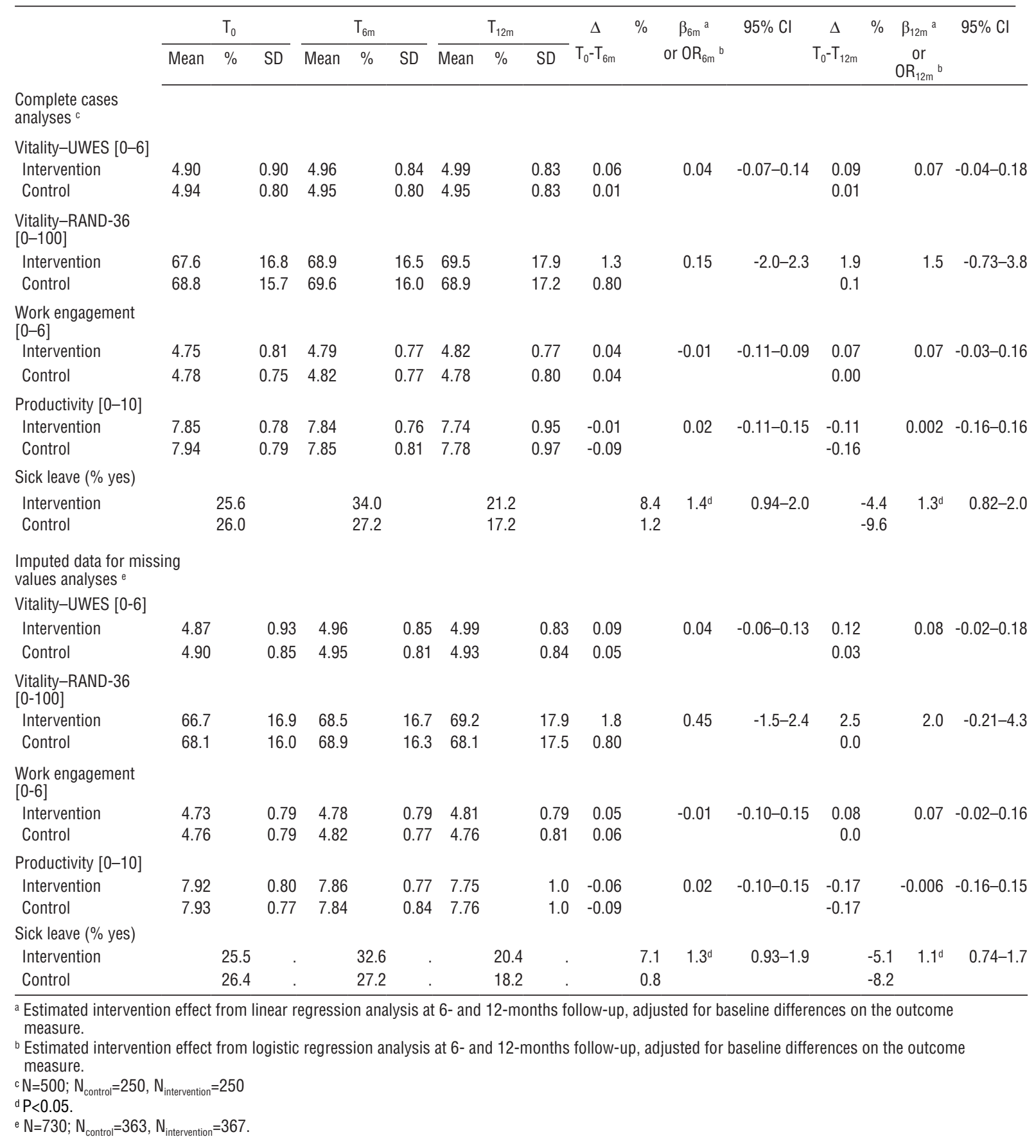


Table 3. Long-term effectiveness (ie, 12 months after baseline) for yoga and workout session compliance [N=number of older workers; $95 \% \mathrm{Cl}=95 \%$ confidence interval subgroups]

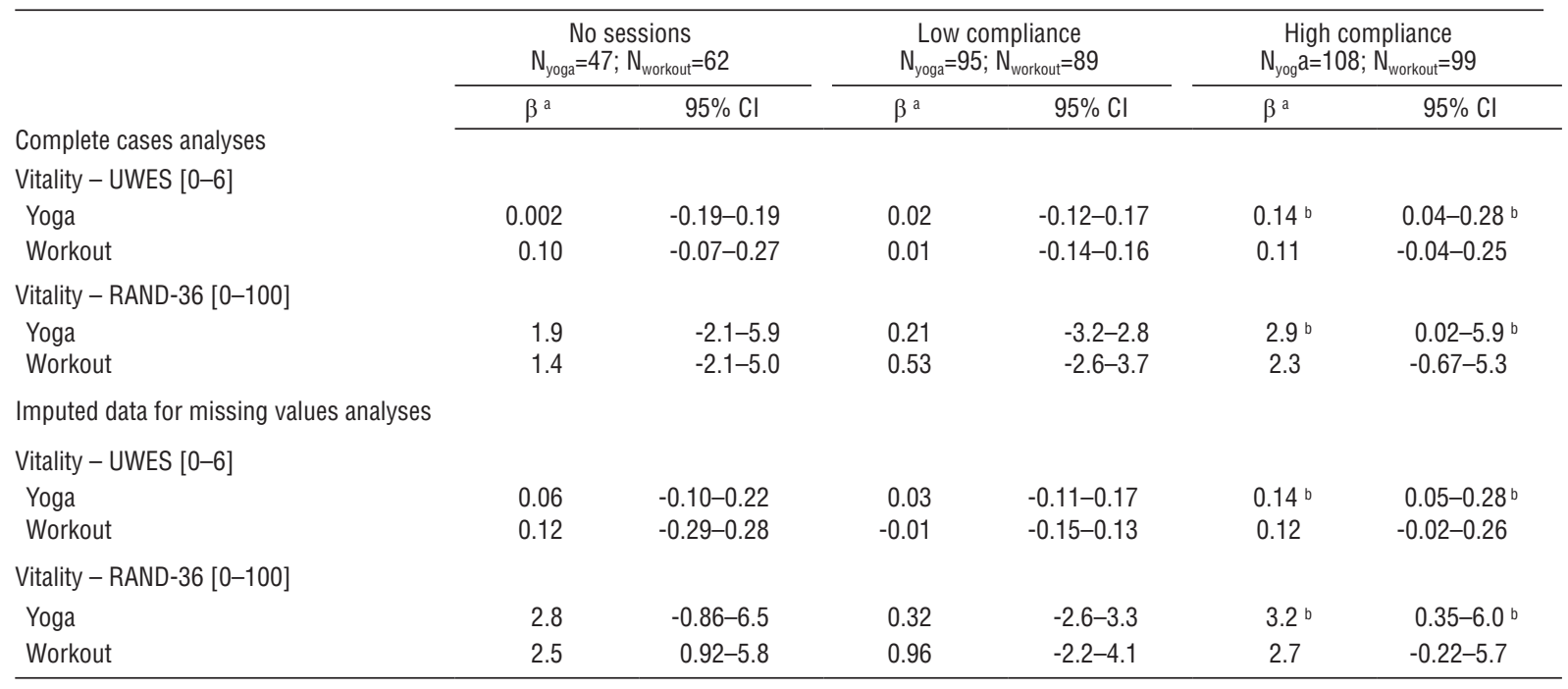

${ }^{a} \beta=$ estimated intervention effect from linear regression analyses.

b $\mathrm{P}<0.05$.

The lack of impact of the Vital@Work intervention on work-related outcomes could possibly be explained by factors concerning the study population and the degree of implementation of the intervention. As for the study population, we studied a relatively healthy group of workers. Healthier workers are more likely to stay in the workforce than those who are sick or physically unfit (ie, healthy worker effect) (45). This may be especially true for older hospital workers as the majority of this population has to deal with higher physical workloads than an average Dutch worker. A two-yearly survey among Dutch workers indeed showed that hospital workers are healthier when compared to the average Dutch worker (46). Support for this was also found in the mean values of the main outcomes, which corresponded to the upper limit range of those measures (ie, ceiling effect). Moreover, a recent study has shown that the UWES had difficulty in differentiating respondents with high work engagement (47), making it more difficult to distinguish small differences between study groups. This could also have been the case for productivity (ie, WHO-HPQ) and general vitality (ie, RAND-36). As to the degree of implementation, the emphasis in intervention studies is mostly placed on effectiveness (48). This may increase the risk for type-III-error, namely to assume that there is no effect of an intervention when actually the intervention was not fully implemented as planned (49). To gain insight into the degree of implementation, a process evaluation was conducted alongside the evaluation of the Vital@Work intervention (50). Results from this pro- cess evaluation showed that the implementation of the intervention was accomplished as planned with respect to the dose delivered (ie, guided yoga and workout sessions: $72.3 \%$ and $96.3 \%$, respectively, personal vitality coach visits: $100 \%$ ). However, the compliance rates (ie, dose received, yoga: 10.4 sessions/24 weeks, workout: 11.1 sessions/24 weeks) and the attendance rate (yoga: $51.7 \%$, workout: $44.8 \%$ ) were lower than expected. (50). The most reported reason for not attending the guided group sessions was a lack of time (both yoga and workout). This could imply that when the intervention was fully implemented as intended (eg, maximizing compliance and thereby the dose received), the intervention might possibly show favorable effects, such as those seen among the high yoga compliers.

Some limitations of this study can be indicated. First, data were obtained solely from questionnaires. As a result, all data were self-reported, inducing a potential risk of bias due to socially desirable answers. Second, the external validity (ie, generalizability) of the study may be questionable, as the intervention was specifically tailored to older hospital workers. Another limitation is that the power calculation was based on work-related vitality and may, therefore, be too small to detect significant differences in other outcomes measures, for instance sick leave. A last limitation may be the loss to follow-up rates found after 12-month (ie, about $30 \%$ ), which is a common problem among prevention studies (51). The 12-month loss to follow-up rate may have induced selection bias (52). However, there were 
neither dissimilarities at baseline between completers and non-completers nor the two study groups for all outcome measures, nor for any confounding factors. Also, imputed data analyses showed similar, but smaller estimated intervention effects compared to complete cases analyses. This is commonly seen with imputation data (41). Hence, conclusions drawn from both complete cases and imputed data analyses were comparable. So, it seems that the loss to follow-up rate of our study did not result in selection bias.

There are also strengths worth mentioning. First, to our knowledge, this is the first study that investigated the effectiveness of a worksite vitality intervention consisting of yoga and aerobic exercising on relevant work-related outcomes. This was also the first study to investigate these outcomes specifically among older workers. Another strength is the follow-up of one year, making it possible to evaluate both short- and longterm effectiveness. Further strengths are the large study sample of 730 older workers and the study design, ie, a randomized controlled trial.

The key findings of our study are that a worksite intervention consisting of yoga and aerobic exercise, provision of free fruit, and individual coaching sessions did not result in improvements in work-related outcomes. Therefore, it cannot be recommended to implement the current Vital@Work intervention as a tool to improve older workers' vitality, work engagement, productivity, or sick leave. Future research should focus on identifying further relevant factors that may lead to improvements in vitality and work engagement. Given the forthcoming labor shortage, it is important to identify these factors to ensure older workers are active members of the workforce. Further, as high yoga compliance showed effects on both work-related and general vitality, this deserves to be explored further in future research. For instance, it would be interesting to investigate other possible positive effects of worksite yoga interventions on work-related outcomes related to employability, such as job performance or job satisfaction. As only high yoga compliance showed positive effects, it is important to find effective means to stimulate compliance. As a possible solution to overcome the most important reason for not participating in the intervention (ie, a lack of time), employers should consider to offer employees WHP programs during paid working time (53). Although employers may associate this with productivity loss, good worker health might have the potential to enhance company profitability (54). In fact, a recent study showed that when employees worked out during work hours, productivity levels were improved (55). In addition, impeding factors for participation should be investigated in more detail in future research. Also, due to the supposed healthy worker and ceiling effects, it would be interesting to investigate effective- ness of yoga and aerobic exercising among a more diverse population with respect to vitality and work engagement, for instance, workers with higher risks in terms of sick leave, productivity or disability pension.

\section{Concluding remarks}

As the workforce is rapidly ageing, effective tools are necessary to promote healthy labor participation of older workers. The results of this study showed no effects on vitality, work engagement, productivity, or sick leave, but they did show that high compliance with guided yoga sessions favorably affected vitality. Implementation of worksite yoga facilities could be a useful strategy to promote vitality-related work outcomes but only if high compliance can be maximized. Therefore, impeding factors for participation should be investigated in more detail in future research.

\section{Acknowledgements}

The Vital@Work study is financially supported by the Foundation Institute GAK. The trial is registered at the Dutch Trial Register (NTR) under trial registration number: NTR1240 (http://www.trialregister.nl/trialreg/ admin/rctview.asp?TC=1240).

The authors declare that they have no competing interests.

\section{References}

1. Organisation for Economic Co-operation and Development (OECD). OECD Annual Report 2007. 31-46. 2007. Paris, OECD Publications.

2. von Bonsdorff ME, Huuhtanen P, Tuomi K, Seitsamo J. Predictors of employees' early retirement intentions: an 11year longitudinal study. Occup Med (Lond). 2010;60(2):94 100. http://dx.doi.org/10.1093/occmed/kqp126.

3. Rice NE, Lang IA, Henley W, Melzer D. Common health predictors of early retirement: findings from the English Longitudinal Study of Ageing. Age Ageing. 2011;40(1):5-61. http://dx.doi.org/10.1093/ageing/afq153.

4. Ilmarinen JE, Tuomi K, Klockars M. Changes in the work ability of active employees over an 11-year period. Scand J Work Environ Health. 1997;23 Suppl 1:49-57.

5. Ilmarinen JE, Tuomi K. Work ability of aging workers. Scand J Work Environ Health. 1992;18 Suppl 2:8-10.

6. Kessler RC, Greenberg PE, Mickelson KD, Meneades LM, Wang PS. The effects of chronic medical conditions on work loss and work cutback. J Occup Environ Med. 2001;43(3):218-25. http://dx.doi.org/10.1097/00043764200103000-00009 
7. Shirom A. Feeling energetic at work: On vigor's antevendents. In: Bakker A, Leiter M, editors. Work Engagement: recent developments in theory and research. New York, NYC: Psychology Press; 2010.

8. Ryan RM, Frederick C. On energy, personality, and health: subjective vitality as a dynamic reflection of well-being. J Pers. 1997;65(3):529-65. http://dx.doi. org/10.1111/j.1467-6494.1997.tb00326.x.

9. McNair D.M., Lorr M., Droppleman L.F. Manual for the profile of mood states. San Diego: Educational and Industrial Testing Service; 1971.

10. McHorney CA, Ware JE, Jr., Raczek AE. The MOS 36-Item Short-Form Health Survey (SF-36): II. Psychometric and clinical tests of validity in measuring physical and mental health constructs. Med Care. 1993;31(3):247-63. http:// dx.doi.org/10.1097/00005650-199303000-00006.

11. Schaufeli WB, Bakker AB. Utrecht Work Engagement Scale. Occupational Health Psychology Unit Utrecht University 2003.

12. Strijk JE, Proper KI, van der Beek AJ, van Mechelen W. The Vital@Work Study. The systematic development of a lifestyle intervention to improve older workers' vitality and the design of a randomised controlled trial evaluating this intervention. BMC Public Health. 2009;9:408. http://dx.doi. org/10.1186/1471-2458-9-408.

13. Bouchard C, Shephard RJ. Physical activity, fitness, and health: the model and key concepts. In: Bouchard C, Shephard RJ, Stepehns T. Physical activity, fitness and health. International proceedings and consensus statement. Champaign: Human Kinetics Books; 1994.

14. Penedo FJ, Dahn JR. Exercise and well-being: a review of mental and physical health benefits associated with physical activity. Curr Opin Psychiatry. 2005;18(2):189-93. http:// dx.doi.org/10.1097/00001504-200503000-00013.

15. Van Duyn MA, Pivonka E. Overview of the health benefits of fruit and vegetable consumption for the dietetics professional: selected literature. J Am Diet Assoc. 2000;100(12):1511-21. http://dx.doi.org/10.1016/S0002-8223(00)00420-X.

16. Shephard RJ. Exercise and relaxation in health promotion. Sports Med. 1997;23(4):211-7. http://dx.doi. org/10.2165/00007256-199723040-00001.

17. Rehm J, Room R, Graham K, Monteiro M, Gmel G, Sempos CT. The relationship of average volume of alcohol consumption and patterns of drinking to burden of disease: an overview. Addiction. 2003;98(9):1209-28. http://dx.doi. org/10.1046/j.1360-0443.2003.00467.x

18. Strijk JE, Proper KI, Klaver L, van der Beek AJ, van Mechelen W. Associations between VO2max and vitality in older workers: a cross-sectional study. BMC Public Health. 2010;10(1):684. http://dx.doi.org/10.1186/1471-2458-10684.

19. Smith C, Hancock H, Blake-Mortimer J, Eckert K. A randomised comparative trial of yoga and relaxation to reduce stress and anxiety. Complement Ther Med. 2007;15(2):77-83. http://dx.doi.org/10.1016/j.ctim.2006.05.001.
20. Sharma R, Gupta N, Bijlani RL. Effect of yoga based lifestyle intervention on subjective well-being. Indian J Physiol Pharmacol. 2008;52(2):123-31.

21. Chen KM, Chen MH, Chao HC, Hung HM, Lin HS, Li CH. Sleep quality, depression state, and health status of older adults after silver yoga exercises: Cluster randomized trial. Int J Nurs Stud. 2009;46(2):154-63. http://dx.doi.org/10.1016/j. ijnurstu.2008.09.005.

22. Ross A, Thomas S. The health benefits of yoga and exercise: a review of comparison studies. J Altern Complement Med. 2010;16(1):3-12. http://dx.doi.org/10.1089/acm.2009.0044.

23. Granath J, Ingvarsson S, von TU, Lundberg U. Stress management: a randomized study of cognitive behavioural therapy and yoga. Cogn Behav Ther. 2006;35(1):3-10. http:// dx.doi.org/10.1080/16506070500401292.

24. Nurminen E, Malmivaara A, Ilmarinen J, Ylostalo P, Mutanen $\mathrm{P}$, Ahonen $\mathrm{G}$, et al. Effectiveness of a worksite exercise program with respect to perceived work ability and sick leaves among women with physical work. Scand J Work Environ Health. 2002;28(2):85-93. http://dx.doi.org/10.5271/ sjweh.652.

25. Schultz AB, Chen CY, Edington DW. The cost and impact of health conditions on presenteeism to employers: a review of the literature. Pharmacoeconomics. 2009;27(5):365-78. http:// dx.doi.org/10.2165/00019053-200927050-00002.

26. Schultz AB, Edington DW. Employee health and presenteeism: a systematic review. J Occup Rehabil. 2007;17(3):547-79. http://dx.doi.org/10.1007/s10926-007-9096-x.

27. Hughes SL, Seymour RB, Campbell RT, Shaw JW, Fabiyi C, Sokas R. Comparison of two health-promotion programs for older workers. Am J Public Health. 2011;101(5):883-90. http://dx.doi.org/10.2105/AJPH.2010.300082

28. Conn VS, Hafdahl AR, Cooper PS, Brown LM, Lusk SL. Metaanalysis of workplace physical activity interventions. Am J Prev Med. 2009;37(4):330-9. http://dx.doi.org/10.1016/j. amepre.2009.06.008

29. Pronk NP, Boyle RB, O'Connor PJ. The association between physical fitness and diagnosed chronic disease in health maintenance organization members. Am J Health Promot. 1998;12(5):300-6. http://dx.doi.org/10.4278/0890-117112.5.300.

30. Ni Mhurchu C, Aston LM, Jebb SA. Effects of worksite health promotion interventions on employee diets: a systematic review. BMC Public Health. 2010;10:62. http://dx.doi. org/10.1186/1471-2458-10-62

31. Cancelliere C, Cassidy JD, Ammendolia C, Cote P. Are workplace health promotion programs effective at improving presenteeism in workers? A systematic review and best evidence synthesis of the literature. BMC Public Health. 2011;11:395. http://dx.doi.org/10.1186/1471-2458-11-395.

32. Kuoppala J, Lamminpaa A, Husman P. Work health promotion, job well-being, and sickness absences--a systematic review and meta-analysis. J Occup Environ Med. 2008; 50(11):121627. http://dx.doi.org/10.1097/JOM.0b013e31818dbf92.

33. Proper KI, Staal BJ, Hildebrandt VH, van der Beek AJ, van 
Mechelen W. Effectiveness of physical activity programs at worksites with respect to work-related outcomes. Scand J Work Environ Health. 2002;28(2):75-84. http://dx.doi. org/10.5271/sjweh.651.

34. Schaufeli WB, Dijkstra P. Bevlogen aan het werk. [Engaged at work].1st ed. Utrecht (the Netherlands): Thema uitgeverij van Schouten en Nelissen; 2010.

35. Strijk JE, Proper KI, van der Beek AJ, van Mechelen W. A worksite vitality intervention to improve older workers' lifestyle and vitality-related outcomes: results of a randomised controlled trial. J Epidemiol Community Health. 2012 Jan 20. [Epub ahead of print]. http://dx.doi.org/10.1136/jech-2011200626.

36. Shephard RJ. PAR-Q: Canadian Home Fitness Test and exercise screening alternatives. Sports Med. 1988;5(3):18595. http://dx.doi.org/10.2165/00007256-198805030-00005.

37. Pollock ML, Gaesser GA, Butcher JD, Després JP, Dishman RK, Franklin BA, et al. ACSM Position Stand: The Recommended Quantity and Quality of Exercise for Developing and Maintaining Cardiorespiratory and Muscular Fitness, and Flexibility in Healthy Adults. Medicine \& Science in Sports \& Exercise. 1998;30(6):975-91. http://dx.doi. org/10.1097/00005768-199806000-00032.

38. van der Zee KI, Sanderman R. Het meten van gezondheidstoestand met de RAND-36: een handleiding. [Measuring health status using the RAND-36 questionnaire: a practical manual]. Groningen: Noordelijk Centrum voor Gezondheidsvraagstukken; 1993.

39. Kessler RC, Barber C, Beck A, Berglund P, Cleary PD, McKenas D, et al. The World Health Organization Health and Work Performance Questionnaire (HPQ). J Occup Environ Med. 2003;45(2):156-74. http://dx.doi.org/10.1097/01. jom.0000052967.43131.51.

40. Koopmanschap MA. PRODISQ: a modular questionnaire on productivity and disease for economic evaluation studies. Expert Rev Pharmacoecon Outcomes Res. 2005;5(1):23-8. http://dx.doi.org/10.1586/14737167.5.1.23.

41. Hollis S, Campbell F. What is meant by intention to treat analysis? Survey of published randomised controlled trials. BMJ. 1999;319(7211):670-4. http://dx.doi.org/10.1136/ bmj.319.7211.670.

42. Azur MJ, Stuart EA, Frangakis C, Leaf PJ. Multiple imputation by chained equations: what is it and how does it work? Int J Methods Psychiatr Res. 2011;20(1):40-9. http://dx.doi. org/10.1002/mpr.329.

43. van Buuren S. Multiple imputation of discrete and continuous data by fully conditional specification. Stat Methods Med Res. 2007;16(3):219-42. http://dx.doi. org/10.1177/0962280206074463.
44. Rubin D. Multiple imputation for nonresponse in surveys. New York: John Wiley \& Sons; 1987. http://dx.doi. org/10.1002/9780470316696.

45. Li CY, Sung FC. A review of the healthy worker effect in occupational epidemiology. Occup Med (Lond). 1999;49(4):225-9. http://dx.doi.org/10.1093/ occmed/49.4.225.

46. Hesselink J, Koppes L, Pleijers A, De Vroome E. De nationale enquete arbeidsomstandigheden (NEA) 2009. [The Dutch working conditions survey 2009]. Hoofddorp: TNO Work \& Health, 2010

47. Shimazu A, Schaufeli WB, Miyanaka D, Iwata N. Why Japanese workers show low work engagement: An item response theory analysis of the Utrecht Work Engagement scale. Biopsychosoc Med. 2010;4:17. http:// dx.doi.org/10.1186/1751-0759-4-17.

48. Saunders RP,Evans MH,JoshiP. Developing a process-evaluation plan for assessing health promotion program implementation: a how-to guide. Health Promot Pract. 2005;6(2):134-47. http://dx.doi.org/10.1177/1524839904273387.

49. Dobson P, Cook T. Avoiding type III error in program evaluation: results from a field experiment. Evaluation and Program Planning. 1980;3(4):269-76. http://dx.doi. org/10.1016/0149-7189(80)90042-7.

50. Strijk JE, Proper KI, van der Beek AJ, van Mechelen W. A process evaluation of a worksite vitality intervention among ageing hospital workers. Int J Behav Nutr Phys Act. 2011;8(1):58. http://dx.doi.org/10.1186/1479-5868-8-58.

51. Galea S, Tracy M. Participation rates in epidemiologic studies. Ann Epidemiol. 2007;17(9):643-53. http://dx.doi. org/10.1016/j.annepidem.2007.03.013.

52. Higgins J, Green S. Cochrane handbook for systematic reviews of interventions version 5.0.1.[Internet]. The Cochrane collaboration, 25 March 2012..

53. Linnan LA, Sorensen G, Colditz G, Klar DN, Emmons KM. Using theory to understand the multiple determinants of low participation in worksite health promotion programs. Health Educ Behav. 2001;28(5):591-607. http://dx.doi. org/10.1177/109019810102800506.

54. Goetzel RZ, Ozminkowski RJ. The health and cost benefits of work site health-promotion programs. Annu Rev Public Health. 2008;29:303-23. http://dx.doi.org/10.1146/annurev. publhealth.29.020907.090930.

55. von Thiele SU, Hasson H. Employee self-rated productivity and objective organizational production levels: effects of worksite health interventions involving reduced work hours and physical exercise. J Occup Environ Med. 2011;53(8):838 44. http://dx.doi.org/10.1097/JOM.0b013e31822589c2

Received for publication: 10 October 2011 